\title{
The Role of Arab Fathers in Heritage Language Maintenance in New Zealand
}

\author{
Morad Al-Sahafi ${ }^{1}$ \\ ${ }^{1}$ Faculty of Arts and Humanities, King Abdulaziz University, Jeddah, Saudi Arabia \\ Correspondence: Morad Al-Sahafi, Faculty of Arts, King Abdulaziz University, Jeddah 21589, Saudi Arabia. \\ E-mail: m.alsahafi@gmail.com
}

Received: November 6, 2014 Accepted: November 28, 2014 Online Published: January 27, 2015

doi:10.5539/ijel.v5n1p73 URL: http://dx.doi.org/10.5539/ijel.v5n1p73

\begin{abstract}
This paper aims to explore Arab immigrant fathers' language attitudes and practices toward their children's heritage language maintenance in New Zealand. Using a questionnaire and semi-structured interviews, data were collected from 10 Arab immigrant fathers of children aged 14 and under, all living with their families in Auckland. Semi-structured in-depth interviews were used to gain insight into the participants' language attitudes and practices toward their children's heritage language maintenance. The findings reveal that the participants were very positive toward the heritage language and its maintenance. Although the participants differed in their countries of origin, Arabic, as a pluricentric language, seems to operate as a unifying core cultural value (Smolicz, 1981) that intertwines with other core values such as religion and ethnic consciousness. While emphasizing the complementary nature of their own and their wives' roles in the process of heritage language maintenance, the participants highlighted some of their key roles and contributions as Arab Muslim immigrant fathers in the process of heritage language intergenerational maintenance, such as explicitly setting and monitoring family language policy, establishing co-ethnic contacts, and providing Arabic materials to enhance Arabic literacy learning among their children.
\end{abstract}

Keywords: Arabic, fathers, heritage language maintenance, identity, immigrant, language attitudes

\section{Introduction}

New Zealand is a linguistically and culturally diverse country with immigrants from different parts of the world. Usually, immigrant families arriving in their new places of relocation do find themselves members of a minority group interacting with a more powerful majority group which is culturally and linguistically different. Such ethnolinguistic differences can threaten the ethnic and linguistic continuity of the immigrant family (Fishman, 1989). In such immigrant minority contexts, heritage language maintenance becomes one of the major challenges faced by many immigrant families in the host society (Fishman, 1991; Tannenbaum \& Howie, 2002). The term language maintenance refers to the situation when members of a minority ethnolinguistic group 'continue to use their language in some or all spheres of life despite competition with the dominant or majority language to become the main/sole language in these spheres' (Pauwels, 2004, p. 719).

Research on immigrant children in numerous multilingual contexts around the world shows that maintaining a stable active bilingualism in the minority (L1) and majority (L2) language is difficult to achieve because as soon as immigrant children become exposed to the L2 in their host society, they are more likely to experience a gradual process of language shift toward the L2 (Clyne, 2003; Fillmore, 1991; Kaufman, 2001; Pauwels, 2005; Shin, 2005). Thus, the dilemma facing immigrant children, as described by Fillmore (2000) and others, may be viewed as less a problem of learning the dominant mainstream language than of heritage language loss.

It is to be noted, however, that language maintenance is not an all or nothing matter. Different minority language families in different contact settings can achieve different degrees of success in maintaining their heritage language among their children. Researchers have identified a number of factors that might account for differential success in heritage language maintenance among immigrant minority communities (e.g., Clyne, 1982; Kloss, 1966; Smolicz, 1981, among others). In the New Zealand context, for example, Holmes, Roberts, Verivaki and 'Aipolo (1993) identified a number of factors conducive to heritage language maintenance among Tongan, Greek and Chinese speech communities including: (a) regular social interaction between community members, (b) use of the community language in the home, (c) positive attitudes to the language and a high value placed on 
it in relation to ethnic identity, (d) community identified religious organization, and (e) a positive orientation to the homeland.

Previous research on heritage language maintenance highlights the importance of the role of the immigrant family in the retention of heritage language and cultural identity among immigrant children (Barkhuizen, 2006; Luo \& Wiseman, 2000; Park \& Sarkar, 2007; Taft \& Cahill, 1989; Tannenbaum \& Howie, 2002; Zhang, 2004). As Fishman (1991) puts it, 'It is in the family that the peculiar bond with language and language activities (conversation, games, stories, songs, proverbs...) is fostered, shared and fashioned into personal and social identity' (p. 409). Immigrant parents (and their ethnic community) often tend to act as language planning agents on behalf of their children in the country of immigration and consequently their attitudes and practices affect the acquisition and maintenance of both L1 and L2 by their children (Barkhuizen \& Knoch, 2006; Hatoss, 2008). While some parents tend to emphasise the importance of the heritage language and choose to shoulder the burden of passing it on to their children, other parents regard the home language as a problem and thus encourage their children to shift to the majority language in order to accelerate their children's assimilation in the host society (Ruiz, 1984; see also Aikio, 1992; Tuominen, 1999).

However, research addressing the potential role of the father in heritage language maintenance within immigrant families is relatively scarce. Most of the studies in this area have focused either on the role of 'parents' as an entity (Bradshaw, 2006; Yamamoto, 2003) or primarily on the role of mothers (Aikio, 1992; Mills, 2004). In her study of home language transmission in a Swiss-German-speaking family in Australia, Schupbach (2006) found that it was the father who explicitly set the family language policy (e.g., designating Swiss-German the language of the home) and tried to enforce it. More recently, Kim and Starks (2010) report that Korean immigrant fathers in New Zealand play a significant role in deciding the home language in their families. According to the researchers, the centrality of the Korean father in home language use and maintenance might be attributed to the nature of the Korean family structure and, in particular, to the role (and authority) of the father in the family.

Similarly, in typical Arab families, fathers act as the guardians of their families and chief providers and consequently they usually play a visible and active role in parenting (see Dwairy et al., 2006 for a discussion of parenting styles in Arab societies). The present study aims to explore the language attitudes and practices of Arab Muslim immigrant fathers toward heritage language maintenance for their New Zealand's raised children.

\section{New Zealand Arabic-Speaking Community}

Arab immigrants constitute a relatively recent immigrant minority group in New Zealand whose number increased considerably during the 1990s. Major causes of Arab immigration to New Zealand over the past decades include the Arab-Israeli conflict, the first Gulf war (1990-1991), the 2003 invasion of Iraq (also known as the second Gulf war), and other pull factors of immigration such as pursuit of a better life and joining other family members. Arabic, the first language of New Zealand Arab immigrants, is spoken as a first language by more than 300,000,000 people in the world (Suleiman, 2003). Therefore, as a pluricentric language (Abd-el-Jawad, 1992; Clyne \& Kipp, 1999), Arabic has been brought to New Zealand by Arab immigrants from a range of different Arab countries, including Iraq, Syria, Egypt, Jordan, Tunisia, and Morocco.

Although Arab immigrants belong to different national backgrounds, it is a common place to refer to 'Arab' or 'Arab Muslim' immigrants as an entity (Elkholy, 1966; Rouchdy, 2002). For example, in his study of Arab Muslim immigrants in the United States, Elkholy noted that Arab Muslim immigrants 'feel a common cultural, religious, and linguistic bond, in addition to the geographical and historical connection, with the Arab countries' (1966, p. 49).

In the New Zealand context, counts of Arabic-speaking immigrants almost doubled between the 1996 and 2001 census years. The 2001 census data (Statistics New Zealand) show that 7959 respondents claimed to be first-language Arabic speakers. The figure continued to rise, but at a slower rate, between 2001 and 2013. Language data obtained from the 2013 census (Statistics New Zealand) show that 10746 respondents claimed to be first-language Arabic speakers. The largest number of these immigrants have chosen to reside in Auckland, the country's biggest and most cosmopolitan city.

It is to be noted that the Arabic language in the New Zealand Arabic-speaking community, and elsewhere, exists in a diglossic situation, which is manifested through the co-existence of Standard and Colloquial Arabic (Al-Sahafi \& Barkhuizen, 2006). These two genetically related Arabic varieties are in complementary distribution with each other. While Standard Arabic is used in formal settings such as education and religion, Colloquial Arabic (a collective term for Arabic spoken varieties) is allocated to informal everyday life interaction. Thus, in the course of the current study, the context usually helped to distinguish which variety of Arabic the participants refer to: Standard or Colloquial Arabic. The next section provides some background information 
about the study's participants as well as a description of the research methods employed in the study.

\section{Method}

\subsection{Participants}

Ten Arab Muslim immigrant fathers residing in Auckland with their families participated in this study (see Table 1). They were first generation Arab immigrants and ranged from 36 years to 57 years of age. While six of the participants arrived in New Zealand together with their families, the other four migrated singly for a period of time ranging from a few months to a few years before sending for their wives and children 'in order to investigate the possibility of migration and to do the necessary preparation' (Hassan) (Note 1.) Their length of residence ranged between 4 and 13 years with an average of nearly 9 years of residency in New Zealand. Their levels of education are relatively high and vary from secondary education to postgraduate level. They worked in a variety of occupations (e.g., painter, taxi driver, shopkeeper, shop owner and lecturer). Two of them reported being unemployed at the time of the study.

The participants' English proficiency varied. Although the majority of the parents reported that they had reached a certain level of functional English proficiency that allowed them to handle their everyday affairs, only three of them (Yusuf, Jamal and Uthman) described themselves as proficient bilinguals in Arabic and English. Nevertheless, all of the parents, like many first generation Arab immigrants in New Zealand, described Arabic as their first language and the language they felt most comfortable with. When asked about their spouses' language background, all of the fathers reported that their spouses were Arabic dominant. The participants were recruited through the Arabic heritage language school in Auckland.

Table 1. Participants' details

\begin{tabular}{lllll}
\hline Participant & Age & Country of birth & Education & Time in NZ \\
\hline 1. Ibrahim & 39 & Jordan & Undergraduate & 4 yrs \\
2. Yusuf & 57 & Syria & Diploma & $12 \mathrm{yrs}$ \\
3. Jamal & 45 & Iraq & Undergraduate & $11 \mathrm{yrs}$ \\
4. Mohammed & 40 & Morocco & Undergraduate & $13 \mathrm{yrs}$ \\
5. Ali & 45 & Tunisia & Secondary & $12 \mathrm{yrs}$ \\
6. Saleh & 50 & Tunisia & Diploma & $9 \mathrm{yrs}$ \\
7. Hassan & 36 & Jordan & Undergraduate & 4 yrs \\
8. Abdullah & 51 & Syria & Diploma & 7 yrs \\
9. Uthman & 52 & Iraq & Postgraduate & $10 \mathrm{yrs}$ \\
10. Hamza & 48 & Jordan & Secondary & 6 yrs \\
\hline
\end{tabular}

\subsection{Data Collection and Analysis}

Data collection and analysis proceeded simultaneously. Each of the 10 father participants was interviewed separately twice: a first major interview and a second follow-up interview after each father participant had read his first interview transcript. The interviews were semi-structured and in-depth, designed to focus the communication process reasonably and acceptably on participants' language-related experiences in the host country, their language attitudes and practices toward children's heritage language maintenance. Before the interviews commenced, consent was given by all of the participants, who were then encouraged to select the interview site that was convenient for them. Interviews were conducted in a variety of settings such as participants' homes, the researcher's home, and the Arabic heritage school in Auckland.

I gave the participants the option of speaking either Arabic or English. Seven of them chose Arabic. Three fathers, who described themselves as proficient Arabic-English bilinguals, chose English. Each interview was audio-recorded and lasted between 75 and 100 minutes. After conducting each interview, I requested my interviewees to fill out a short questionnaire to collect some demographic data. Following Flick's advice, the questionnaire was administered after the interview 'in order to prevent its structure of questions and answers from imposing itself on the dialogue in the interview' (2002, p. 88).

The second follow-up interview took place within 6 weeks of each father's first interview, after he had read his first interview transcript. Applying member checks aimed to give the participants an opportunity for reflection and rumination before conducting follow-up interviews (see Maxwell, 1996). The second interviews lasted from 18 to 40 minutes.

Following procedures of qualitative data analysis (Miles \& Huberman, 1994), the interview transcripts were 
analyzed in order to code and categorise the main themes evident in the interviews. Recurrent themes relevant to the focus of the current study will be used as the basis for the analysis and discussion provided in the next section, which will be supported by verbatim excerpts from the transcripts in order 'to keep the human story in the forefront of the reader's mind and to make the conceptual analysis more accessible to a wider audience' (Charmaz, 1995, p. 47). The English translation of the Arabic interview excerpts used in this paper was done by the author, who is a native speaker of Arabic and proficient Arabic-English bilingual.

\section{Findings}

Of course we are originally Arabs. We try to give the good image of Islam and the good image of Arabs. We explain to them that we are peaceful. We have history. We have a rich culture. We have civilization and this civilization has something to offer to other civilizations. And we are people with history knowledge and we value our origin and culture. (Yusuf, I1) (Note 2)

The findings revealed that the parents in this study had positive attitudes toward encouraging their children's progress in both Arabic and English. According to them, learning English should not necessarily mean losing Arabic among their children. Through the interviews, the parents reflected strong valuing of the Arabic language and culture, which seemed to initiate and fuel their language maintenance efforts at the family and community level. The above excerpt from Yusuf's interview reflects the views of these Arab fathers who appeared to be assertive about their rights as a minority immigrant group to preserve their home language and culture. At the same time, they were equally aware of the complexity of the process of language maintenance as well as of potential challenges and opportunities, as will be discussed.

In the following subsections, three interrelated sources of parents' positive attitudes toward the heritage language and its maintenance for their children will be discussed:

- Heritage language as an essential ethnic, national and religious identity marker;

- Heritage language maintenance as a good fathering practice;

- Heritage language as an essential factor for enhancing family and cultural ties.

These sources of parental attitudes are based on the themes that emerged through an analysis of the data as described above. They represent the major reasons behind parental positive attitudes toward the heritage language and its maintenance.

\subsection{Heritage Language Maintenance and Identity}

The parents introduced the issue of multiple identities as they reflected on their multiple roles and subject-positions as Arabs, Muslims and fathers living with their families in an immigrant multilingual context. These various features of their identity are interrelated and were a major influence in the way they perceived their role in their children's cultural and linguistic upbringing. One of the most commonly mentioned reasons why the parents in this study attached great importance to Arabic was the perceived connection between Arabic and their identity. All the parents indicated that their children should maintain the Arabic language and culture in order to keep their Arabic and Muslim identity. This theme of a connection between the Arabic language and identity was strongly articulated by the participants, who regarded themselves as belonging to one Arabic-speaking nation extending from the Arabian Gulf to the North African shores of the Mediterranean.

The Arabic-speaking community in New Zealand represents a microcosm of the Arab world where Arabic and religion play a major role in identity construction. When asked about their identity, all parents in this study described themselves as Arabs and Muslims. For them, the Arabic tongue was the most fundamental component of their identity. For example, Jamal thought that knowing Arabic was what separated Arabs from Ajams (Note 3): 'If you lose the Arabic tongue, then you are not an Arab; you will become an Ajam' (I1). According to Abdullah, maintaining Arabic was important for both Muslim and non-Muslim Arabs because Arabic constituted a major marker of ethno-Arab belonging:

What defines an Arab is primarily the Arabic tongue. Even Non-Muslim Arab immigrants in the North Shore (Note 4) are keen to teach Arabic to their children while they have their own tenets and practices as Christians. So, as long as the person is an Arab, either Muslim or Christian, you find him maintain his Arabic. (I1)

Thus, the Arabic language, Standard Arabic in particular, contributed to the creation of a sense of shared Arabness among the participants and therefore acted as a major marker of the national spirit (pan-Arabism) among them. Hamza asserted, 'We are Arabs and this is what brings us together. Saying this is from this country and this is from that country is what brings us down' (I1). Arabic therefore acted as a bond of solidarity that 
reinforced a feeling of 'us' versus 'them.'

As the language of Islam, Arabic also played an important role as a factor connecting ethnic identity and religious identity for these Arab Muslim fathers. The following excerpt from Ali's interview illustrates this well:

Loss of the Arabic language entails loss of identity. For us, the Arabic language represents the title of our culture. And when Arabic is lost, it becomes extremely difficult to understand religion, and it becomes very difficult to get in touch with members of the Arabic-speaking community. By losing our language we lose our religion and this is a danger that threatens us and therefore it is important for us to have regular schools where our children can learn Arabic on a daily basis. (I1)

According to the participants, being an Arab represented a small circle within a larger circle which represented their Islamic identity, as part of the larger Muslim Ummah (nation). When asked how they felt about Arab immigrant children who lost their Arabic language, the fathers' responses included such expressions as: 'sad and sorrowful' (Hassan, I1), 'pity' (Yusuf, I1), and 'really sorry' (Uthman, I1). The participants also indicated that loss of Arabic could lead to loss of ethnic and religious identity among Arab immigrant children. As Abdullah explained:

When the child loses his Arabic skills, what remains of his Arab identity? I mean that there is a certain minimum level of Arabic that the child should know. A child's loss of Arabic ability entails loss of his Arabness. If the child does not know Arabic, how can he pray? When an Ajam enters Islam, we say to him, 'come and learn some Arabic so that you can pray.' (I1)

Hamza stated more explicitly that 'the Arabic language and Islam are inseparable' (I2). The impact of Islam on the maintenance and intergenerational transmission of Arabic (Arabic literacy in particular) is well documented in the literature (see Clyne \& Kipp, 1999; Fishman, 1991; Rouchdy, 2002). Due to its strict association with Islam, Standard Arabic enjoys a symbolic significance to Muslims in general and to Arab Muslims in particular as the only authentic means of religious expression. Clyne and Kipp point out that this sacred character of the language gives not only the religious variety, but also the corresponding colloquial variety, 'a special status and authenticity' (1999, p 330). The Arabic language, therefore, serves as a core value that intertwines with other core values such as religion and historical consciousness. According to Clyne (2003), the role of language as a core value is usually enhanced in such situations, i.e. when language is linked with other cultural core values, since this would necessitate the use of language for particular purposes such as using Arabic for reading the Qur'an and performing the five daily prayers.

It is to be noted, however, that the participants' active process of constructing their identity as well as the intergenerational transmission process of identity among their families did not take place in isolation. Macro-level influence in an increasingly globalised world seemed to have an impact on the local context for these Arab Muslim fathers and their families. Although the participants said that they generally felt well accepted in their personal and family life in New Zealand, some of them appeared to be under the impression that the media sometimes portrayed Arabs and Muslims in a stereotypical manner, particularly after some of the world major events such as the 9/11 (2001) New York and 7/7 (2005) London events. For example, Saleh said, 'of course, the media is the main factor, especially for New Zealand people. People here are very respectful; they are nice to strangers and they are not racist. But what the media have done since 2001 is something terrible'(I1).

Some parents reported their personal experiences with regard to some perceived anti-Arab and anti-Muslim stereotyping. For example, Mohammed shared his own experience by stating:

Yes I have seen and experienced this myself, especially after the attacks on the United States. Some people started to call us and anyone with a beard Taliban (Note 5). After the Iraq problem, New Zealand people became more aware of the Arab community and how it differs from that of Taliban. (I2)

In this excerpt, Mohammed pointed out that Muslims did not constitute a homogeneous group. He also explained how some of the dramatic world events (e.g., the Taliban movement in Afghanistan and the so-called 'war on terror') had influenced the micro-level context for Arab Muslims living in New Zealand. Clearly, the process of identity-construction among these participants seemed to involve both how they identified (and made) themselves and were identified (made) by others. This observation is in accord with the reference made by another participant to what appeared to be a coordinated series of attacks against six Islamic centres in Auckland in July, 2005. (Note 6)

Therefore, as Kolig and Shepard (2006) rightly observe, despite the conspicuousness of Muslims as an immigrant group in New Zealand, the most obvious impact on them is generated by rather major international 
events (e.g., the events of 9/11 and 7/7), "which have brought New Zealand Muslims into the focus of, often unfavourable, attention, in an otherwise pluralist, multicultural, multi-religious and laissez-faire tolerant society' (p. 4).

\subsection{Heritage Language Maintenance and Fathering}

With regard to their decisions to transmit Arabic to their children, the father participants in this study indicated that it was among their responsibilities as Arab Muslim fathers to ensure that their children learned and retained the Arabic language, particularly the standard form of Arabic with its high status connotations as the shared and religious code. Developing children's Arabic religious literacy appeared to be an important motivating factor that promoted the process of Arabic teaching to their children. For example, Ibrahim, among others, considered the transmission of Arabic to his children as one of his responsibilities to his children as an Arab Muslim father:

Indeed passing the language on to our children is among the children's rights over us. Among the rights of the child over the father are three: To choose a good mother for him, to select good name to him and to teach him the Quran. And the Qur'an is in Arabic, so then it is essential to teach the child Arabic. (I2)

When asked specifically how they perceived their role as fathers in passing on the Arabic language and culture to their children, the participants conveyed certain key roles:

- Setting, monitoring and enforcing the family language policy: Fathers as managers

I have noticed that they [his children] sometimes use English with each other at home. I asked them to use Arabic. I say: use Arabic, use Arabic! They respond to me and shift to Arabic but, I can tell, they find it difficult and they feel under pressure when being pushed to do so. But, you know, you cannot watch them all the time. When I am around and they feel my presence they tend to use Arabic. (Ali, I2)

Ali's comment on his family language policy reflected one of the ways these men responded to their role in the process of heritage language intergenerational maintenance. This comment also depicts how these men perceived the importance of their authority, as fathers, to set and enforce their home language policy. Another participant, Yusuf, explicitly explained that the father acted as 'the manager: Giving advice, implementing rules, telling them [children] how to give the good image. So while the role of the mother is important, you still need the father to guide' (I1).

Notwithstanding a reported constant struggle to enforce an Arabic-only home environment, these fathers appeared to be aware that their children did not always follow their family's language rules and expectations since English was reported as the preferred language for child-child interaction, particularly when parents are not around. Jamal, for example, seems to face a bigger father-child conflict with his 14-year-old son. As a father, Jamal feels that his authority is challenged by his son who has grown up in New Zealand.

Our children have learnt the English language and the New Zealand culture. They are not like us anymore. You sometimes notice that your son speaks to you as your equal. You say to him, 'do this!' He then replies, 'why?' This is something we, as fathers, haven't experienced before. We need to get used to this new reality and to adapt to this new culture because we grew up there [in the home country].

In the previous excerpt, Jamal felt that his authority as the father in the family is challenged by his teenage child whose frame of reference is shaped by the lessons he learned from his English mainstream school, classmates, and media input in the host society. Indeed, heritage language maintenance frequently produces parent-child conflict as children, particularly older ones, learn and emphasize cultural values, linguistic choices and behaviours that sometimes conflict with those of their parents. Portes and Rumbaut (2001, p. 52) refers to such intergenerational conflict as 'generational dissonance' which might lead to a decline of parental authority within immigrant families.

- Providing Arabic learning materials for the children: Fathers as providers

His [the father's] role includes providing Arabic resources and giving advice and guidance. Of course, all this occurs in consultation between him and the mother as they complement each other. (Abdullah, I1)

In this excerpt, Abdullah, among others, indicated that a key responsibility for the father was to provide Arabic learning resources (e.g., Arabic books, videos, DVDs, etc.) for his children. This new role developed as an extension of the Muslim father's role as the chief provider and the one responsible for the welfare of the family. 
It also emerged as a response to Arab Muslim fathers' new parental role as language planning agents on behalf of their children in the host country.

- Ensuring family participation in ethnic community events and activities: Fathers as socializing agents

He [the father] can do many things including taking children to the Arabic [heritage] school, taking them to Arab social gatherings, providing a supportive climate at home, choosing friends and socializing with those Arab families which maintain Arabic. Let's say social gatherings and family picnics, any activity within the Arabic-speaking community. All these activities encourage children to preserve their language and culture. (Hamza, I2)

Hamza's view highlighted the primary role of Arab-Muslim immigrant fathers in the socialization patterns of their families in the new country. While the mother/housewife played a primary role in children's upbringing, the father, as the guardian of the family, had an important role in connecting with co-ethnics through participation in a variety of ethnic activities and events such as weddings, social gatherings, family picnics, and heritage school.

On the other hand, when asked how they perceived the role of their wives (and mothers of their children) in the process of Arabic language and culture transmission, all of the fathers emphasised strongly the complementary nature of fathers' and mothers' contributions and engagements with children's linguistic upbringing. For example, Saleh stated that children's language maintenance was a shared parental responsibility: 'I say that the father and the mother play major roles and they both have joint contributions to children's language transmission in the diaspora. It is a shared responsibility and a shared burden' (I1). Generally, all fathers in this study emphasised the role of the mother in heritage language and culture intergenerational transmission. For example, Yusuf noted that, 'I'm not living with children 24 hours. She is with them. Most of the day, I'm outside the home due to responsibility of the community, of my work. So, the mother I think is the key person' (I1).

In short, the fathers in this study viewed the promotion of Arabic maintenance among their children as a good parenting practice through which they attempted to fulfil part of their new roles and responsibilities as Arab Muslim fathers in the country of immigration.

\subsection{Language Maintenance, Family Cohesion and Cultural Transmission}

As noted previously, findings show that the parents strongly desired to maintain and transmit their home cultural values and traditions to their children. In this connection, as Yusuf noted, the Arabic language acted as a bridge that connected Arab children to their ethno-religious culture:

As I said, Arabic is the means to understand our culture and our religion and to keep contact with the culture because as soon as you lose the mother tongue, your relationship with the culture, with the family comes to an end. So if they return home they will not be able to understand the language of their grandparents. (I1)

Clear in Ali's comment was the idea of 'a return to the homeland.' This idea of going back to the home country in the future, e.g., when the political situation and circumstances changed, was mentioned by some of the participants and appeared to motivate their home language and culture maintenance efforts.

In addition, since Arab-Muslim values emphasise strong family and social ties, it is not surprising that all the fathers in this study stressed the vital role of the Arabic language as a bridge that promoted family cohesion, co-ethnic networks and transnational ties. In this regard, communication with grandparents and other relatives in the homeland via telephone or during family visits was part of this process of maintaining (extended) family cohesion that could only be achieved through the use of Arabic. According to Hassan, among other parents, one of the major functions of the Arabic language was its employment for co-ethnic communication in the new country:

When the child loses his Arabic, he then loses the religious side and the social side. He loses his past and contacts with his relatives...There are many customs and traditions that constitute part of our culture and if the child doesn't know them, he will suffer a major problem with regard to his future personality traits. The Arabic language represents the transmitter of these traits; for example, generosity and hospitality. (I1)

As clearly expressed in this excerpt, Arabic was regarded as a reflection and a transmitter of ethno-religious culture customs and traditions. Arab immigrant children's knowledge of Arabic was therefore perceived to be crucial in maintaining a connection with their ethno-religious culture. As noted by Hassan, Arabic was not only regarded as a means of communication, but also as a cultural vehicle to transmit such ethnic values and traditions as strong family/kin relations, generosity and hospitality to subsequent generations. Children's knowledge of 
Arabic was also perceived to be crucial to access and understand the cultural heritage, e.g., stories, proverbs, and poetry associated with these values and traditions. Cultural heritage knowledge, in turn, acted as a source of emotional and practical support for immigrant children because, as explained by Mohammed, 'it answers important questions about who they are. What is their origin? It gives them pride. So they are not just like nothing. They have good history and good origin' (I2).

Another participant, Saleh, further argued that the transmission of the original culture helped build self-confidence and a stronger personality among Arab children and therefore could help protect children against the pulling power of the mainstream culture and equip them to avoid negative assimilation in the host society:

If the child is of an Arab origin and becomes unable to speak and understand Arabic, he will not be then able to know his Arabic culture. Then, the other stream will pull him in its direction and the danger emerges from this door. Knowing the original culture and keeping contact with it lead to stronger personality and more self-confidence. And this is true for any culture. (I1)

Thus, although these parents differed in their countries of origin, Arabic as a pluricentric language seemed to operate as a unifying core cultural value that was essential for group membership. A similar role of the Arabic language among different groups of Arabic-speaking immigrants in Australia and the United States has been reported (See Clyne \& Kipp, 1999; Rouchdy, 2002).

\section{Conclusion}

This study explores the language attitudes and practices of Arab Muslim immigrant fathers toward heritage language maintenance of their children. By and large, the participants showed very positive attitudes toward the Arabic language and its maintenance among their New Zealand-raised children. They all viewed Arabic as an important marker of their own and their children's ethnic and religious identity, which seemed to constitute a pivotal axis in their identity structure. This ethno-religious dimension of their identity operated as a group identity marker that accentuated ethnic group consciousness and consequently delineated ethnic group boundaries.

The findings show that the Arabic language is perceived as a central or core value (Smolicz, 1981) that is linked with other core values such as family, religion and ethnic consciousness. Retention and transmission of this ethno-religious identity would promote the intergenerational transmission of Arabic due to the strong association between ethnicity, religion, and language among immigrant Arab Muslim families generally (Clyne, 2003; Clyne \& Kipp, 1999; Rouchdy, 2002). Additionally, the Arabic language seems to act as a unifying force among Arabic-speaking immigrants and consequently contributes to their sense of 'shared Arabness.' Thus, as a base of networking, the Arabic language provides one aspect of commonality for Arab immigrants that transcend other possible aspects such as country of origin.

Intergenerational heritage language maintenance is viewed as part of the Arab Muslim immigrant father's responsibilities in the host society. In this connection, setting and enforcing family language policy in the form of using only Arabic in the home reflects one of the ways the participants respond to their role in the process of heritage language maintenance, which seems to be implemented more successfully in parent-child interaction than among the children themselves. It should be noted, however, that parent-child interaction in the domain of the family usually covers quite limited topics for Arabic use which is, in many cases, insufficient for age-appropriate expression. Therefore, it is important that the parents provide a communication-rich Arabic language environment for their children. For example, families can make use of modern communication technology such as the Internet to provide their children with plenty of Arabic interaction with relatives and friends in the home country. In addition, families can utilize and encourage their children to use Arabic resources on the Internet (e.g., newspapers, magazines) to maximize the children's exposure to up-to-date uses of Arabic, particularly in such a country as New Zealand where Arabic is not yet visible in the public domain. Such opportunities for Arab immigrant children to regularly use the heritage language in its spoken and written forms can contribute to its promotion and maintenance, when appropriate parental guidance and support are provided.

Finally, it is important to note that the participants in this study represent only one subgroup of New Zealand Arabic-speaking immigrants, i.e. Arab Muslims. Research, therefore, is needed to explore parental language attitudes among other subgroups of Arabic-speaking immigrants in New Zealand such as non-Arab Muslims who maintain Arabic as a religious variety and Arabic-speaking families of non-Muslim backgrounds in order to investigate the impact of such factors as religion and ethnicity on the process of heritage language maintenance. 


\section{References}

Abd-el-Jawad, R. H. (1992). Is Arabic a pluricentric language? In M. Clyne (Ed.), Pluricentric languages (pp. 261-304). Berlin: Mouton de Gruyter.

Aikio, M. (1992). Are women innovators in the shift to a second language? A case study of Reindeer Sami women and men. International Journal of the Sociology of Language, 94, 43-61. http://dx.doi.org/10.1515/ijsl.1992.94.43

Al-Sahafi, M. A., \& Barkhuizen, G. (2006). Language use in an immigrant context: The case of Arabic in Auckland. New Zealand Studies in Applied Linguistics, 12(1), 51-69.

Barkhuizen, G. (2006). Immigrant parents' perceptions of their children's language practices: Afrikaans speakers living in New Zealand. Language Awareness, 15, 63-79. http://dx.doi.org/10.1080/09658410608668851

Barkhuizen, G., \& Knoch, U. (2006). Macro-level policy and micro-level planning [Electronic Version]. Australian Review of Applied Linguistics, 29. http://dx.doi.org/10.2104/aral0603

Bradshaw, J. (2006). Parent and child perspectives on Greek language education in Australia. International Journal of the Sociology of Language, 180, 43-54.

Charmaz, K. (1995). Grounded theory. In J. A. Smith, R. Harre, \& L. V. Langenhove (Eds.), Rethinking methods in psychology (pp. 27-49). London: Sage. http://dx.doi.org/10.4135/9781446221792.n3

Clyne, M. (1982). Multilingual Australia. Melbourne, Australia: River Seine Publications.

Clyne, M. (2003). Dynamics of language contact. Cambridge: Cambridge University Press. http://dx.doi.org/10.1017/CBO9780511606526

Clyne, M., \& Kipp, S. (1999). Pluricentric languages in an immigrant context: Spanish, Arabic and Chinese. Berlin/New York: Mouton de Gruyter. http://dx.doi.org/10.1515/9783110805444

Dwairy, M., Achoui, M., Abouserie, R., Farah, A., Sakhleh, A. A., Fayad, M., \& Khan, H. K. (2006). Parenting Styles in Arab Societies: A First Cross-Regional Research Study. Journal of Cross-Cultural Psychology, 37, 230-247. http://dx.doi.org/10.1177/0022022106286922

Elkholy, A. A. (1966). The Arab Moslems in the United States: Religion and assimilation. New Haven, CN: College and University Press.

Ferguson, C. A. (1959). Diglossia. Word, 15, 325-340.

Fillmore, L. W. (1991). When learning a second language means losing the first. Early Childhood Research Quarterly, 6, 323-346. http://dx.doi.org/10.1016/S0885-2006(05)80059-6

Fillmore, L. W. (2000). Loss of family languages: Should educators be concerned? Theory into Practice, 39, 203-210. http://dx.doi.org/10.1207/s15430421tip3904_3

Fishman, J. A. (1989). Language and ethnicity in minority sociolinguistic perspective. Clevedon: Multilingual Matters.

Fishman, J. A. (1991). Reversing language shift. Clevedon: Multilingual Matters.

Flick, U. (2002). An introduction to qualitative research. London: Sage.

Hatoss, A. (2008). Community-level approaches in language planning: The case of Hungarian in Australia. In A. J. Liddicoat, \& R. B. Baldauf (Eds.), Language planning in local contexts (pp. 55-74). Bristol: Multilingual Matters.

Holmes, J., Roberts, M., Verivaki, M., \& Aipolo, A. (1993). Language maintenance and shift in three New Zealand speech communities. Applied Linguistics, 14, 1-24. http://dx.doi.org/10.1093/applin/14.1.1

Kaufman, D. (2001). Tales of L1 attrition: Evidence from pre-puberty children. In T. Ammerlean, H. Madeleine, H. Strating \& K. Yagmur (Eds.), Sociolinguistic and psycholinguistic perspectives on maintenance and shift of minority languages. New York: Munster.

Kim, S. H. O., \& Starks, D. (2010). The role of Korean fathers in L1 maintenance and L2 learning. International Journal of Bilingual Education and Bilingualism, 13(3), 285-301. http://dx.doi.org/10.1080/13670050903193958

Kloss, H. (1966). German-American language maintenance efforts. In J. A. Fishman (Ed.), Language loyalty in the United States (pp. 206-252). The Hague: Mouton. 
Kolig, E., \& Shepard, W. (2006). Introduction: Muslims in New Zealand. New Zealand. Journal of Asian Studies, $2,1-7$.

Luo, S. H., \& Wiseman, R. L. (2000). Ethnic language maintenance among Chinese immigrant children in the United States. International Journal of Intercultural Relations, 24, 307-324. http://dx.doi.org/10.1016/S0147-1767(00)00003-1

Maxwell, J. A. (1996). Qualitative research design: An interactive approach. Thousand Oaks, CA: Sage.

Miles, M. B., \& Huberman, A. M. (1994). Qualitative data analysis: A sourcebook of new methods (2nd ed.). Newbury, CA: Sage.

Mills, J. (2004). Mothers and mother tongue: Perspectives on self-construction by mothers of Pakistani heritage. In A. Pavlenko \& A. Blackledge (Eds.), Negotiation of identities in multilingual contexts (pp. 161-191). Clevedon: Multilingual Matters.

Park, S. M., \& Sarkar, M. (2007). Parents' attitudes toward heritage language maintenance for their children and their efforts to help their children maintain the heritage language: A case study of Korean-Canadian immigrants. Language, Culture and Curriculum, 20(3), 223-235. http://dx.doi.org/10.2167/lcc337.0

Pauwels, A. (2004). Language maintenance. In A. Davies and C. Elder (Eds.), The handbook of applied linguistics (pp. 719-737). Malden, MA: Blackwell. http://dx.doi.org/10.1002/9780470757000.ch29

Pauwels, A. (2005). Maintaining the community language in Australia: Challenges and roles for families. The International Journal of Bilingual Education and Bilingualism, 8, 124-131. http://dx.doi.org/10.1080/13670050508668601

Portes, A., \& Rumbaut, R. G. (2001). Legacies: The story of the immigrant second generation. Berkeley: University of California Press.

Rouchdy, A. (2002). Language conflict and identity: Arabic in the American diaspora. In A. Rouchdy (Ed.), Language contact and language conflict in Arabic: Variations on a sociolinguistic theme (pp. 133-148). London: RoutledgeCurzon.

Ruiz, R. (1984) Orientations in language planning. NABE Journal, 8(2), 15-34.

Schupbach, D. (2006). "It's something that's just faded away": How a Melbourne family of Swiss-German background makes sense of language shift. International Journal of the Sociology of Language, 180, $89-104$.

Shin, S. J. (2005). Developing in two languages: Korean children in America. Clevedon: Multilingual Matters.

Smolicz, J. (1981). Core values and cultural identity. Ethnic and Racial Studies, 4, 75-90. http://dx.doi.org/10.1080/01419870.1981.9993325

Statistics New Zealand. (2013). New Zealand Census of Population and Dwellings: Language spoken (Total responses). Retreived from http://stats.govt.nz

Suleiman, Y. (2003). The Arabic language and national identity. Washington, DC: Georogetown University Press.

Taft, R., \& Cahill, D. (1989). Mother tongue maintenance in Lebanese immigrant families in Australia. Journal of Multilingual and Multicultural Development, 10, 129-143. http://dx.doi.org/10.1080/01434632.1989.9994369

Tannenbaum, M., \& Howie, P. (2002). The association between language maintenance and family relations: Chinese immigrant children in Australia. Journal of Multilingual and Multicultural Development, 23, 408-424. http://dx.doi.org/10.1080/01434630208666477

Tuominen, A. (1999). Who decides the home language? A look at multilingual families. International Journal of the Sociology of Language, 140, 59-76. http://dx.doi.org/10.1515/ijsl.1999.140.59

Yamamoto, M. (2003). Language use in families with parents of different native languages: An investigation of Japanese-non-English and Japanese-English families. Journal of Multilingual and Multicultural Development, 23, 531-554. http://dx.doi.org/10.1080/01434630208666484

Zhang, D. (2004). Home language maintenance among second-generation Chinese American families. Working Papers in Educational Linguistics, 19, 33-53. 


\section{Notes}

Note 1. All names are pseudonyms.

Note 2. (In):The index code given to each interview excerpt shows the parent's interview number (I1 or I2).

Note 3. Ajam is an Arabic word which means non-Arabic speakers.

Note 4. North Shore City (or informally the North Shore) is one of the four cities in the Auckland metropolitan area.

Note 5. Taliban, which literally means 'students,' is an Islamic political movement that ruled Afghanistan from 1996 to until 2001.

Note 6. On 10 July, 2005, Auckland's Muslim community found six mosques vandalised and walls tagged in graffiti with the message "Londoners Rip" following the terrorist 7/7 bombings in London.

\section{Copyrights}

Copyright for this article is retained by the author(s), with first publication rights granted to the journal.

This is an open-access article distributed under the terms and conditions of the Creative Commons Attribution license (http://creativecommons.org/licenses/by/3.0/). 